\title{
Fluorometric Determination of Cadmium in Polyvinyl Chloride Stabilizers and Polyvinyl Chloride in Nonaqueous Media
}

\author{
Javier Galban, Susana de Marcos, Juan C. Vidal, Carmelo Diaz and Jose Aznarez \\ Analytical Chemistry Department, Faculty of Sciences, University of Zaragoza, Zaragoza-50009, Spain
}

\begin{abstract}
A method for the fluorometric determination of cadmium(II) is proposed. The metal reacts with Calcein in $N, N$ dimethylformamide and the cadmium(II)-Calcein complex formed presents an emission maximum at $534 \mathrm{~nm}$ and several excitation maximum, the determination being carried out at an excitation wavelength of either $519 \mathrm{or} 496 \mathrm{~nm}$. Over the range $1-70 \mathrm{ng} \mathrm{ml}^{-1}$, the fluorescence intensity is linear with the cadmium(II) concentration; the obtained precision (relative standard deviation) is about $4 \%$. The proposed method permits the determination of cadmium(II) at the trace level. The method was applied to the determination of cadmium in cadmium organic salts, polyvinyl chloride (PVC) thermal stabilizers and PVC polymers.
\end{abstract}

Keywords Fluorometry, nonaqueous media, cadmium determination, Calcein, polyvinyl chloride

In the industrial field, cadmium is one of the elements that has more versatility. Its applications, whether in pure elements or in the form of organic or inorganic salts, include such areas as semiconductor technology, solder, batteries, corrosion or plastic industries. In this last field, two main uses stand out: as a colorant (cadmium sulfide) and as a polyvinyl chloride (PVC) stabilizer (cadmium organic salts).

The use of cadmium as a PVC polymer stabilizer has been widely extended during the last decades. The discovery of its harmful characteristics has lead to a search for substances that can replace it. Unfortunately cadmium is still being widely and increasingly used. ${ }^{1}$ Cadmium stabilizers for PVC are commercially available in two different forms. In the solid state, they are mixed organic salts of barium and cadmium, whose organic form anions are acid radicals with a large number of carbon atoms (stearate, laurate, palmitate); in the liquid state form, they are usually organic salts mixtures of barium-cadmium-zinc (2-ethylhexanoate, naphtenate, phenolate, benzoate, neodecanoate). The percentage of cadmium in PVC stabilizers is between 2 and 7\%, while PVC stabilized with cadmium salts containing less than $1 \%$.

In spite of the importance of a cadmium determination, few studies have been published about it in this kind of sample. Thus, atomic absorption spectroscopy ${ }^{2-4}$ stands out, though polarography, $\mathrm{X}$-ray spectroscopy ${ }^{7}$ and molecular absorption spectrometry ${ }^{8}$ have also been used.

Calcein, synthesized in 1956 by Diehl and Ellingboe ${ }^{9}$, was primarily used as a metallofluorescent indicator in calcium titrimetric determination. ${ }^{10,11}$ Its use was extended rapidly to molecular fluorescent metal deter- mination; ${ }^{12}$ in this sense, papers by Koerbl ${ }^{13}$ for the fluorometric determination of $\mathrm{Ca}$, and Wallach ${ }^{14}$ for the fluorometric determination of $\mathrm{Al}, \mathrm{Zn}, \mathrm{Co}, \mathrm{Cu}$ and other elements, using Calcein as reagent, should be mentioned. Its acid-base properties ${ }^{15,16}$ and its structure $^{17}$, have also been studied. Calcein is currently being used in fluorometric determinations as an immobilized reagent. ${ }^{18}$

In this work, a spectrofluorometric method for cadmium determination is proposed. The sample is dissolved in $N, N$-dimethylformamide (DMF), without acid attack, and an aliquot of the sample solution is allowed to react with Calcein in DMF. The method has been applied to cadmium determination in cadmium organic salts, PVC stabilizers and a PVC sample.

\section{Experimental}

\section{Apparatus}

All measurements were performed with a Shimadzu model RF 510 spectrofluorophotometer. Excitation and emission slits were set at 3 and $5 \mathrm{~nm}$, respectively. One-centimeter quartz cells were used.

\section{Reagents}

All chemicals used were of analytical-reagent grade, and obtained from Merck.

Cadmium(II) stock solution, $300 \mu \mathrm{g} \mathrm{ml}^{-1}$, prepared from cadmium acetate dihydrate by dissolution in DMF.

Cadmium(II) standard solution, $3 \mu \mathrm{g} \mathrm{ml}^{-1}$, prepared by diluting the stock solution with DMF, immediately before use. 
Calcein solution, $0.03 \%(\mathrm{~m} / \mathrm{v})$ in DMF. Prepared daily.

Organic solvent: ethanol, tetrahydrofurane (THF), acetic acid, dimethylformamide (DMF), pyridine and $t$-butylamine (TBA), were examined.

\section{Organic samples}

"STREM" Sterate and 2-ethylexanoate cadmium salts.

Cadmium-barium and cadmium-barium-zinc PVC stabilizers, and PVC sample obtained gently from "AISCONDEL" were examined.

\section{Procedure}

Place, in a $100 \mathrm{ml}$ flask, an appropriate amount of sample $(0.03-0.04 \mathrm{~g}$ cadmium salts, $0.3-0.4 \mathrm{~g}$ PVC cadmium stabilizer or $2-4 \mathrm{~g}$ PVC) and add $20 \mathrm{ml}$ DMF. Heat in a water bath for $30 \mathrm{~min}$. Allow the solution to cool and dilute it to $100 \mathrm{ml}$ with DMF.

Pipet a portion of the sample, or the cadmium(II) standard solution, containing up to $0.7 \mu \mathrm{g}$ of cadmium (II) into a $10 \mathrm{ml}$ volumetric flask. Add $1 \mathrm{ml}$ of Calcein solution and dilute with DMF. Allow the solution to react for five min. Measure the emission at $534 \mathrm{~nm}$, while keeping the excitation monochromator at 519 or $497 \mathrm{~nm}$. Prepare a blank solution in the same way, but free from cadmium.

\section{Results and Discussion}

Effect of bases and acids on fluorescence intensity

The influence of some organic bases on complex emis-

Table 1 Effect of TBA addition on the emission and excitation complex and reagent wavelengths

\begin{tabular}{ccc}
\hline$\%$ TBA (v/v) & $\lambda_{\text {ex }} / \mathrm{nm}$ & $\lambda_{\text {em }} / \mathrm{nm}$ \\
\hline- & 519 & 534 \\
0.001 & 519 & 534 \\
0.010 & 520 & 535 \\
0.10 & 521 & 535 \\
1.0 & 523 & 539 \\
\hline
\end{tabular}

No changes were observed at $496 \mathrm{~nm}$. [Cd], $20 \mathrm{ng} \mathrm{m}^{-1}$; [Calcein], $1.11 \mu \mathrm{g} \mathrm{ml}^{-1}$.

Table 2 Effect of sulfuric and acetic acids on the emission and excitation wavelengths for the complex and reagent

\begin{tabular}{cccccc}
\hline $\begin{array}{c}\mathrm{H}_{2} \mathrm{SO}_{4}, \\
\%(\mathrm{v} / \mathrm{v})\end{array}$ & $\lambda_{\text {ex }} / \mathrm{nm}$ & $\lambda_{\text {em }} / \mathrm{nm}$ & $\begin{array}{c}\mathrm{CH}_{3} \mathrm{COOH}, \\
\%(\mathrm{v} / \mathrm{v})\end{array}$ & $\lambda_{\text {ex }} / \mathrm{nm}$ & $\lambda_{\text {em }} / \mathrm{nm}$ \\
\hline- & 519 & 534 & - & 519 & 534 \\
$10^{-5}$ & 516 & 534 & $10^{-4}$ & 519 & 534 \\
$10^{-4}$ & 469 & 523 & $10^{-3}$ & 517 & 533 \\
$10^{-3}$ & 469 & 517 & $10^{-2}$ & 516 & 533 \\
$10^{-2}$ & 469 & 516 & $10^{-1}$ & 511 & 525 \\
$10^{-1}$ & 469 & 516 & 1 & 506 & 525 \\
1 & 468 & 516 & 10 & 470 & 523 \\
\hline
\end{tabular}

[Cd], $20 \mathrm{ng} \mathrm{ml}^{-1}$; [Calcein], $1.11 \mu \mathrm{g} \mathrm{ml}^{-1}$. sion was studied. The addition of small amounts of pyridine (about $5 \%$ ) slightly enhances the fluorescence intensity $\left(\% \Delta I=100\left(I_{\text {complex }}-I_{\text {blank }}\right) / I_{\text {blank }}\right)$, but further addition of pyridine causes a sharp decrease; the slight enhancement observed does not justify the use of pyridine in the procedure. Addition of TBA also produces an increase in the emission intensity and a decrease in sensitivity; in this case, the spectral maxima of emission and excitation show shifts to longer wavelength (Table 1).

More than $0.001 \%(\mathrm{v} / \mathrm{v})$ acetic acid and the presence of sulfuric acid in low concentrations $\left(10^{-5} \%(\mathrm{v} / \mathrm{v})\right)$, produces a sharp drop in the sensitivity, and sudden changes in the emission and excitation spectra. Table 2 shows the shift of the maximum emission and excitation wavelengths obtained upon the addittion of sulfuric and acetic acids. This drop becomes sharper when using sulfuric acid (Fig. 1). These effects could be explained on the basis of the change of the hydronium ion concentration, which affects the complexation and fluorescent properties of Calcein.

\section{Effect of organic solvents on fluorescence intensity}

Ethanol produces an emission maximum of both complex and reagent as well as a minimum sensitivity (Fig. 2); likewise, the emission and excitation maxima shift less than with acetic or sulfuric acids. The presence of THF or water produces a similar effect as ethanol, though the addition of larger proportions of THF produces a maximum sensitivity; the spectral changes obtained with THF are less sharp (Table 3).

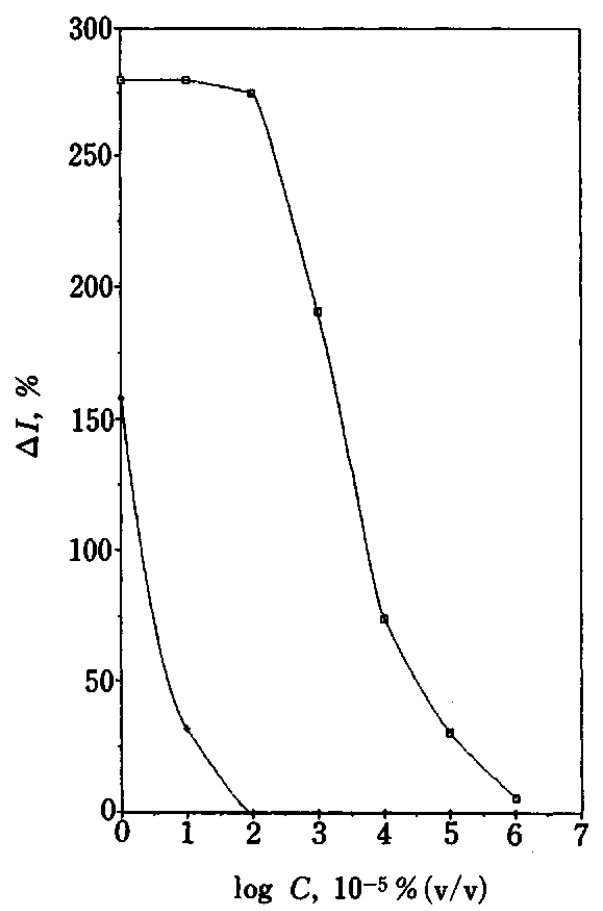

Fig. 1 Fluorescence intensity $\left[\% \Delta I=\left(\left(I_{\text {complex }}-I_{\text {blank }}\right) / J_{\text {blank }}\right) \times\right.$ $100]$ variations of cadmium-Calcein on addition of organic acids: $\square$, acetic acid; $\diamond$, sulfuric acid. Parameters used are those specified in Table 2. 


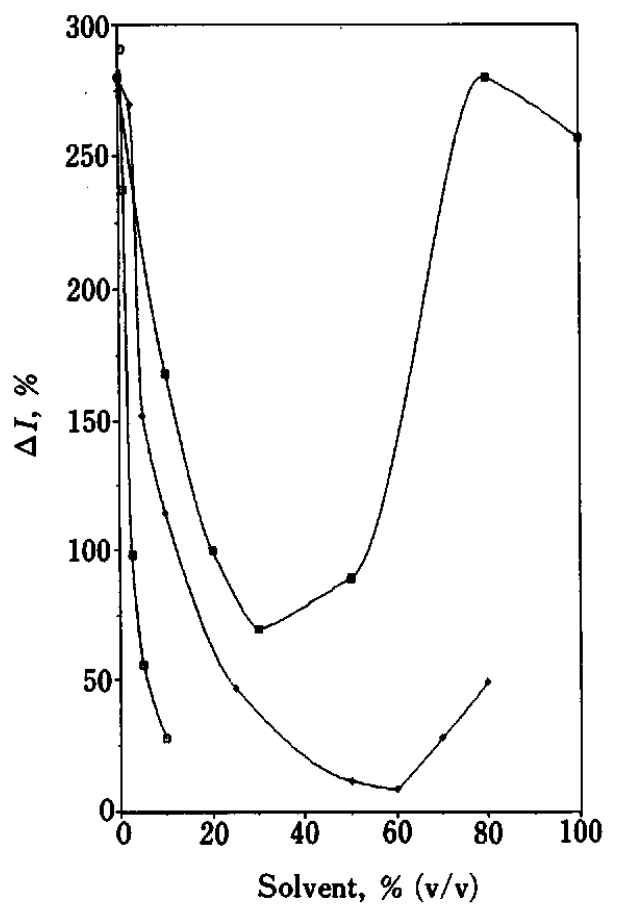

Fig. 2 Fluorescence intensity variations of cadmium-Calcein in ethanol, THF or water: $\bullet$, ethanol; $\square$, THF; $\square$, water. Parameters used are those as specified in Table 3.

Table 3 Effect of THF, water and ethanol on the emission and excitation of the complex and reagent wavelength

\begin{tabular}{|c|c|c|c|c|c|}
\hline $\begin{array}{c}\text { THF, } \\
\%(v / v)\end{array}$ & $\lambda_{\text {ex }} / \mathbf{n m}$ & $\lambda_{\mathrm{em}} / \mathrm{nm}$ & $\begin{array}{l}\text { Water, } \\
\%(v / v)\end{array}$ & $\lambda_{\mathrm{ex}} / \mathrm{nm}$ & $\lambda_{\mathrm{em}} / \mathrm{nm}$ \\
\hline- & 519 & 534 & - & 519 & 534 \\
\hline 10 & 519 & 534 & 0.5 & 519 & 534 \\
\hline 20 & 515 & 532 & 1 & 519 & 534 \\
\hline 30 & 512 & 530 & 2.5 & 518 & 534 \\
\hline 50 & 512 & 530 & 5 & 514 & 532 \\
\hline 80 & 512 & 530 & 10 & 509 & 530 \\
\hline 100 & 511 & 530 & & & \\
\hline \multicolumn{3}{|c|}{ Ethanol, $\%(\mathrm{v} / \mathrm{v})$} & $\lambda_{\mathrm{ex}} / \mathrm{nm}$ & \multicolumn{2}{|c|}{$\lambda_{\text {em }} / \mathrm{nm}$} \\
\hline \multicolumn{3}{|c|}{-} & 519 & \multicolumn{2}{|l|}{534} \\
\hline \multicolumn{3}{|c|}{1} & 519 & \multicolumn{2}{|l|}{534} \\
\hline \multicolumn{3}{|c|}{5} & 519 & \multicolumn{2}{|l|}{534} \\
\hline \multicolumn{3}{|c|}{10} & 514 & \multicolumn{2}{|l|}{532} \\
\hline \multicolumn{3}{|c|}{25} & 508 & \multicolumn{2}{|l|}{527} \\
\hline \multicolumn{3}{|c|}{50} & 497 & \multicolumn{2}{|l|}{521} \\
\hline \multicolumn{3}{|c|}{60} & 497 & \multicolumn{2}{|l|}{520} \\
\hline \multicolumn{3}{|c|}{70} & 496 & \multicolumn{2}{|l|}{520} \\
\hline \multicolumn{3}{|c|}{80} & 496 & \multicolumn{2}{|l|}{520} \\
\hline
\end{tabular}

[Cd], $20 \mathrm{ng} \mathrm{ml}^{-1}$; [Calcein], $1.11 \mu \mathrm{g} \mathrm{ml}^{-1}$.

\section{Effect of reagent concentration and reaction time}

At the wavelength of the maximum emission of a cadmium(II)-Calcein complex in DMF $(534 \mathrm{~nm})$, a blank solution also emits (Fig. 3), probably due to the presence of fluorescein as an impurity. ${ }^{19}$ For that reason the Calcein concentration must be kept to a minimum.
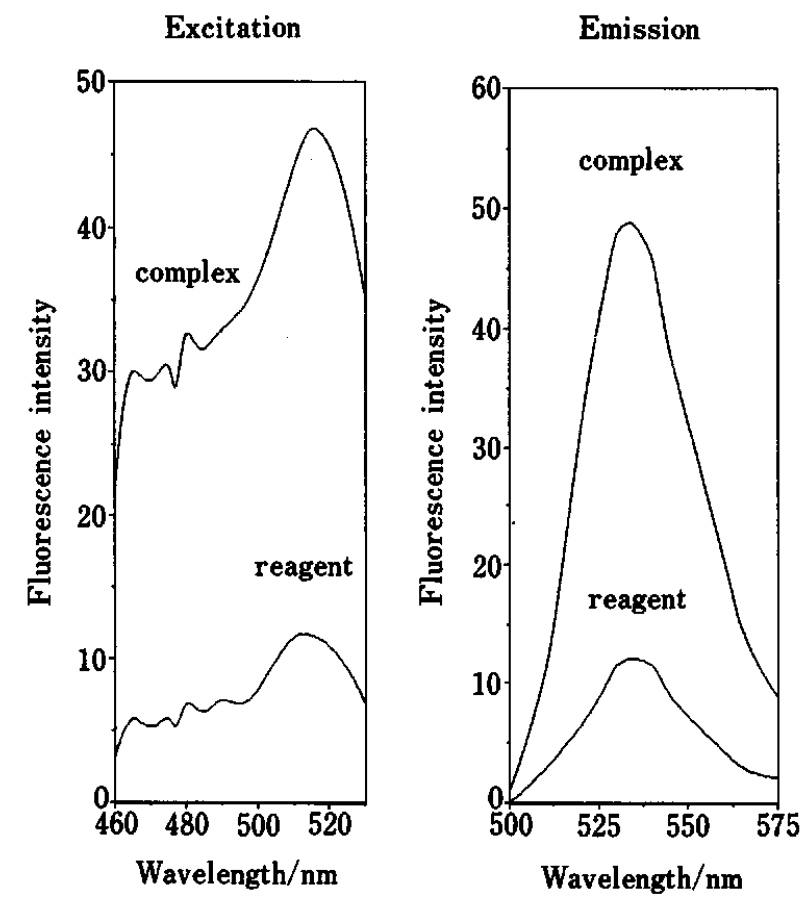

Fig. 3 Cadmium-Calcein complex and calcein alone, emission and excitation spectra in DMF $\left(20 \mathrm{ng} \mathrm{m}^{-1}\right.$ cadmium and $1.11 \mu \mathrm{g} \mathrm{ml}^{-1}$ calcein).

In this work, $1.11 \mu \mathrm{g} \mathrm{ml}^{-1}$ of the reagent was considered as being the optimum. On that condition, the complex was formed in five min; its fluorescence intensity remained constant for at least $90 \mathrm{~min}$.

\section{Calibration graph and precision}

Over the range $1-70 \mathrm{ng} \mathrm{ml}^{-1}$ of cadmium(II) in the final solution, the fluorescence intensity at $534 \mathrm{~nm}$ (519 or $496 \mathrm{~nm}$ excitation wavelength) was linear with the cadmium(II) concentration. The relative standard deviation for ten replicate determinations of $20 \mathrm{ng} \mathrm{ml}^{-1}$ of cadmium was $4 \%$.

\section{Interference study}

The effect of barium and zinc, the only elements associated with cadmium in that kind of samples, was studied. Less than $1 \mu \mathrm{g}$ of barium and $0.6 \mu \mathrm{g}$ of zinc do not interfere in the determination of $0.2 \mu \mathrm{g}$ of cadmium. Larger zinc concentrations do not interfere when $519 \mathrm{~nm}$ is used as the excitation wavelength. These results permit a cadmium determination in PVC cadmium stabilizer samples, since the weight ratio $\mathrm{Ba} / \mathrm{Cd}$ or $\mathrm{Zn} / \mathrm{Cd}$ is less than 1.5.20

\section{Applications}

The method was applied to a cadmium determination in cadmium organic salts (cadmium stearate and cadmium 2-ethylhexanoate) with a certified cadmium content (16.55\% and $28.19 \%$ respectively), in PVC barium-cadmium solid stabilizer and barium-cadmiumzinc liquid stabilizer and in a sample of PVC prepared 
Table 4 Cadmium determination in cadmium organic salts, PVC cadmium stabilizers and PVC sample

\begin{tabular}{|c|c|c|c|c|c|}
\hline \multirow{2}{*}{ Sample } & \multicolumn{3}{|c|}{ Cadmium, $\%$} & \multirow{2}{*}{$\mathrm{RSD}, \%^{\mathrm{a}}$} & \multirow{2}{*}{$\mathrm{RSD}, \%^{\mathrm{b}}$} \\
\hline & Certified & Found $^{\mathrm{a}}$ & Found ${ }^{b}$ & & \\
\hline Stearate & 16.55 & 16.27 & 16.28 & 4 & 3 \\
\hline 2-Ethyl hexanoate & 28.19 & 28.93 & 28.60 & 4 & 3 \\
\hline Stabilizer (Ba-Cd) & - & 5.78 & 5.42 & 4 & 4 \\
\hline Stabilizer (Ba-Cd-Zn) & - & 2.60 & 2.40 & 3 & 3 \\
\hline PVC & 0.28 & 0.31 & 0.30 & 3 & 4 \\
\hline
\end{tabular}

a. $519 \mathrm{~nm}$ excitation wavelength. b. $496 \mathrm{~nm}$ excitation wavelength. RSD, relative standard deviation $(n=10)$.

with the barium-cadmium-zinc stabilizer mentioned above. The obtained results using the standard addition method are presented in Table 4.

\section{References}

1. R. B. Segmour, Rev. Plast. Mod., 356, 211 (1986).

2. D. C. Hunt, Lab. Pract., 24, 411 (1975).

3. J. M. Mendiola and A. Gonzalez Lopez, Rev. Plast. Mod., 289, 431 (1981).

4. M. A. Belarra, M. C. Azofra, J. M. Anzano and J. R. Castillo, J. Anal. At. Spectrom., 3, 591 (1988).

5. N. Molkova and A.I. Kalinin, Zh. Anal. Khim., 27, 1924 (1972).

6. Y. A. Gawargious, S. W. Bishara and B. N. Faltaoos, Indian J. Chem., 12, 1113 (1974).

7. R. Tsunoda, Bull. Chem. Soc. Jpn., 48, 2999 (1975).

8. Analytical Methods Committe, Analyst [London], 94, 1153 (1969).

9. L. Diehl and J. L. Ellingboe, Anal. Chem., 8, 882 (1956).

10. B. M. Tucker, Analyst [London], 82, 284 (1957).
11. R. Pribil, Analyst [London], 83, 188 (1958).

12. A. Fernandez-Gutierrez and A. Muñoz de la Peña, in "Molecular Luminiscence Spectroscopy. Methods and Applications: Part 1", ed. S. G. Schulman, pp. 427-454, John Wiley \& Sons, New York, 1985.

13. J. Koerbl and F. Vydra, Chem. Listy, 51, 1457 (1957).

14. D. Wallach and T. Steck, Anal. Chem., 35, 1035 (1963).

15. D. Wallach, D. M. Surgenor, J. Soderberg and E. Delano, Anal. Chem., 31, 456 (1959).

16. N. Iritani and T. Miyahara, Bunseki Kagaku, 22, 174 (1973).

17. D. B. Martin and H. Diehl, Abs. Pap. A. C. S., 180, 180 (1980).

18. L. A. Saari and W. R. Seitz, Anal. Chem., 56, 810 (1984).

19. A. J. Heffley and B. Jaselskis, Anal. Chem., 46, 2036 (1974).

20. Kirk-Othmer, "Encyclopedia of Chemical Technology", 3rd ed., Vol. 12, p. 241, John Wiley \& Sons, New York, 1978.

(Received October 6, 1989) (Accepted January 20, 1990) 